\title{
Analisis Pengaruh PeranMarketing Public Relationsterhadap Peningkatan Citra Lido Lakes Resort and Conference Sukabumi
}

\author{
Analysis of the Influence of the Marketing Public Relations Roles on the Image \\ Enhancement of Lido Lake Resort and Conference in Sukabumi
}

Efan Septian Saputra ${ }^{1 *}$, Ma'mun Sarma $^{1}$

${ }^{1)}$ Departemen Manajemen, Fakultas Ekonomi dan Manajemen, IPB Kampus Dramaga Bogor 16680

\begin{abstract}
The tourism is a priority sector in Indonesia and reliable source to increase of foreign exchange of the country. Along with the increasing competition of hotel industry especially in Bogor regency, the knowledge about how to make a positive image among society is absolutely important. One of the hotel in the Bogor Regency is Lido Lakes \& Resort Conference Sukabumi. The purposes of this study are to identify the characteristics of the consumer and to analyze Marketing Public Relations (MPR) effects towards image enhancement of Lido Lakes Resort \& Conference Sukabumi. The method of this research are descriptive analysis and Structural Equation Modeling (SEM) with Partial Least Square (PLS) approach. The result of the study showed that publications, social events, and media identity are the variables which positively affects the hotel image. It is therefore recommended for the company to focus on those three significant variables to enhance the hotel image.
\end{abstract}

Key words: hotel, image improvement, marketing public relations, Structural Equation Modelling (SEM).

\begin{abstract}
ABSTRAK
Sektor pariwisata menjadi prioritas di Indonesia dan dapat diandalkan untuk meningkatkan sumber devisa negara. Seiring meningkatnya persaingan industri perhotelan khususnya di Kabupaten Bogor, pengetahuan mengenai cara membentuk suatu citra positif di kalangan masyarakat sangat penting. Salah hatu hotel di Kabupaten Bogor adalah Lido Lakes Resort \& Conference Sukabumi. Tujuan penelitian yaitu mengidentifikasi karakteristik konsumen dan menganalisis pengaruh variabel Marketing Public Relations (MPR) terhadap peningkatan citra yang positif bagi Lido Lakes Resort \& Conference Sukabumi. Analisis data menggunakan analisis deskriptif dan Structural Equation Modelling (SEM) dengan pendekatan Partial Least Square (PLS). Hasil analisis menunjukkan variabel publikasi, kegiatan sosial, dan media identitas berpengaruh positif dan signifikan terhadap citra hotel. Oleh karena itu disarankan perusahaan untuk lebih fokus pada tiga variabel tersebut untuk meningkatkan citra hotel.
\end{abstract}

Kata kunci: hotel, marketing public relations, peningkatan citra, Structural Equation Modelling (SEM).

*Corresponding author

Alamat e-mail: efanseptian.es18@gmail.com 


\section{PENDAHULUAN}

Pariwisata adalah salah satu industri andalan yang harus terus ditumbuh kembangkan oleh suatu negara. Hal ini disebabkan selain pariwisata terbukti dapat menyumbang devisa secara signifikan, memperluas kesempatan kerja dan pendapatan penduduk (Agusnawar, 2004). Saat ini sektor pariwisata sudah menjadi industri yang disebut sebagai industri pariwisata. Industri pariwisata adalah kumpulan dari macam-macam perusahaan yang secara bersama menghasilkan beragam barang dan jasa yang dibutuhkan para wisatawan selama dalam perjalanannya. Kesadaran akan perlunya penanganan yang lebih serius terhadap bidang pariwisata telah melahirkan beberapa kebijakan sebagai langkah pengembangannya.

Peningkatan ekonomi menjadi fokus pemimpin pada negara berkembang.Sebagai dasar untuk membangun negara tersebut, salah satunya adalah dukungan semua sektor ekonomi (Alhroot \& Alhroot, 2013). Sektor pariwisata menjadi prioritas di Indonesia dan dapat diandalkan untuk meningkatkan sumber devisa negara. Pada sektor ini banyak terdapat peluang peluang potensial yang dapat dimanfaatkan karena pada dasarnya daya tarik sebuah wisata itu tidak akan pernah habis dikonsumsi (never ending industry). Sumber terbesar pemasukan devisa dari sektor pariwisata Indonesia berdasarkan dari jumlah wisatawan nasional dapat dilihat pada Tabel 1.

Tabel 1. Perkembangan wisatawan nasional tahun 2009-2013

\begin{tabular}{cccccc}
\hline \multirow{2}{*}{ Tahun } & \multicolumn{2}{c}{ Wisatawan Nasional } & \multicolumn{2}{c}{$\begin{array}{c}\text { Rata-rata Pengeluaran } \\
\text { Per Orang (USD) }\end{array}$} & $\begin{array}{c}\text { Rata-rata } \\
\text { Lama Tinggal } \\
\text { (Hari) }\end{array}$ \\
\cline { 2 - 5 } & $\begin{array}{c}\text { Jumlah } \\
\text { (Orang) }\end{array}$ & $\begin{array}{c}\text { Pertumbuhan } \\
(\%)\end{array}$ & $\begin{array}{c}\text { Per } \\
\text { Kunjungan }\end{array}$ & Per Hari & 8,81 \\
\hline 2009 & 5.053 .269 & - & 977,39 & 09,80 & 8,20 \\
2010 & 6.235 .606 & 23,40 & 976,65 & 17,59 & 7,67 \\
2011 & 6.750 .416 & 8,26 & 934,50 & 21,53 & 7,67 \\
2012 & 7.453 .633 & 10,42 & 926,20 & 27,00 & 6,49 \\
2013 & 7.973 .440 & 9,07 & 912,31 & 40,39 & 8 \\
\hline Rata-rata & 6.373 .231 & 10 & 950 & 22 & \\
\hline
\end{tabular}

Sumber: Pusdatin Kemenparekraf dan BPS, data diolah (2014)

Berdasarkan Tabel 1, perkembangan wisatawan nasional dari tahun 2009-2013 rata-rata adalah sebesar 6.373.231 orang dengan pertumbuhan rata-rata 10 persen. Rata-rata pengeluaran per hari wisatawan adalah sebesar USD122. Rata-rata lama tinggal wisatawan yang berkunjung lamanya adalah delapan hari.

Tabel 2. Pengunjung objek wisata di Kabupaten Bogor tahun 2011-2013 (orang)

\begin{tabular}{cccc}
\hline Wisatawan & 2011 & 2012 & 2013 \\
\hline Wisatawan Mancanegara & 30.669 & 67.658 & 54.927 \\
Wisatawan Nusantara & 3.275 .938 & 2.255 .219 & 4.075 .198 \\
\hline Total & 3.306 .607 & 2.322 .877 & 4.130 .125 \\
\hline
\end{tabular}

Sumber: BPS Kabupaten Bogor (2015)

Berdasarkan Tabel 2, pengunjung objek wisata di Kabupaten Bogor tahun 2011-2013 secara keseluruhan mengalami peningkatan dibanding tahun sebelumnya. Dilihat menurut jenis asal wisatawan, jumlah wisatawan mancanegara (wisman) yang berkunjung ke objek wisata di Kabupaten Bogor pada tahun 2013 mengalami penurunan. Jumlah wisman yang berkunjung ke objek wisata tahun 2012 sebanyak 67.658 orang kemudian turun menjadi 54.927 orang di tahun 2013. Sedangkan jumlah wisatawan nusantara (wisnus) yang berkunjung ke objek wisata di Kabupaten Bogor pada tahun 2013 mengalami peningkatan dari 2,3 juta orang tahun 2012 meningkat hingga mencapai 4,1 juta orang tahun 2013.

Objek wisata yang mendatangkan pengunjung terbesar di Kabupaten Bogor yaitu Taman Wisata Matahari, Taman Safari Indonesia, Wisata Agro Gunung Mas dan Jungle Land di Kecamatan Babakan Madang. Adapun jumlah wisatawan asing yang berkunjung ke objek wisata di Kabupaten Bogor terbesar berkunjung ke objek wisata Taman Safari Indonesia dan Jungle Land, seperti yang dapat dilihat pada Tabel 3. 
Tabel 3. Data kunjungan wisatawan di Kabupaten Bogor tahun 2014

\begin{tabular}{lccc}
\hline \multirow{2}{*}{ Nama Obyek Wisata } & \multicolumn{3}{c}{ Wisatawan (orang) } \\
\cline { 2 - 4 } & Domestik & Asing & Jumlah \\
\hline Taman Safari Indonesia & 1.254 .005 & 1.632 & 1.255 .637 \\
Taman Wisata Matahari & 1.049 .898 & 899 & 1.050 .797 \\
Wisata Agro Gunung Mas & 66.685 & - & 66.685 \\
Jungle Land & 776.918 & 12.061 & 788.979 \\
Curug Nangka & 70.276 & 15 & 70.291 \\
Taman Rekreasi Lido & 17.820 & 25 & 17.845 \\
Agrowisata Bukit hambalang & 22.400 & - & 22.400 \\
Waterpark Kingdom & 165.738 & - & 165.738 \\
\hline
\end{tabular}

Sumber : BPS Kabupaten Bogor (2014)

Sektor pariwisata Indonesia merupakan penggerak perekonomian nasional yang potensial untuk memacu pertumbuhan perekonomian yang lebih tinggi di masa yang akan datang. Pada tahun 2008, pariwisata Indonesia berkontribusi terhadap Produk Domestik Bruto (PDB) sebesar Rp. 153,25 triliun atau 3,09 persen dari total PDB Indonesia BPS, 2010. Pada tahun 2009, kontibusinya meningkat menjadi 3,25 persen. Pada tahun yang sama, devisa dari sektor pariwisata merupakan kontibutor terbesar ketiga devisa negara, setelah minyak dan gas bumi serta minyak kelapa sawit.

Salah satu sarana yang menunjang sektor pariwisata yaitu sarana akomodasi. Jasa perhotelan adalah pendukung sektor pariwisata dalam hal penyediaan akomodasi bagi para wisatawan, dengan produk utamanya berupa pelayanan dan fasilitas penginapan. Hotel menurut Sihite (2000) adalah sejenis akomodasi yang menyediakan fasilitas dan pelayanan penginapan, makan dan minum serta jasa-jasa lainnya untuk umum yang tinggal sementara waktu dan dikelola secara profesional.

Potensi yang cukup besar dalam hal kedatangan tamu ke Kabupaten Bogor, tentunya perlu diimbangi dengan peningkatan penyediaan kamar dan fasilitas penunjang sehingga tidak menimbulkan kesenjangan antara permintaan dan penawaran atas kamar ataupun fasilitas penunjang. Data beberapa hotel berbintang yang menjadi kompetitor hotel Lido Lakes Resort \& Conference (LLRC) disajikan pada Tabel 4.

Tabel 4. Kompetitor hotel Lido Lakes Resort \& Conference

\begin{tabular}{cccccc}
\hline Hotel & $\begin{array}{c}\text { Room } \\
\text { Sold }\end{array}$ & $\begin{array}{c}\text { Room } \\
\text { Average }\end{array}$ & Persentase $(\%)$ & $\begin{array}{c}\text { Average Room } \\
\text { Rate }(\mathrm{Rp})\end{array}$ & Grup \\
\hline Marbella & 138 & 300 & 46,0 & 725.664 & $\begin{array}{c}\text { DINDIK, DINKOP } \\
\text { UMKM } \\
\text { DANAMON, } \\
\text { Imperial }\end{array}$ \\
& 141 & 190 & 74,2 & 777.525 & CIMB BANK \\
\hline Jayakarta & 18 & 31 & 58,1 & 450.112 & FIT \\
Putri Gunung & 97 & 128 & 75,8 & 555.231 & KEMENTRIAN \\
Horizon & 121 & 176 & 68,8 & 521.225 & ESDM \\
\hline Total & 515 & 825 & & & FIT \\
\hline
\end{tabular}

Sumber: Lido Lakes Resort \& Conference (2016)

Seiring meningkatnya persaingan industri perhotelan di Kabupaten Bogor, hal ini membutuhkan kerjasama semua stakeholders LLRC dalam membentuk suatu citra positif di kalangan masyarakat, sehingga dapat memposisikan diri secara tepat sehingga dapat menguasai pangsa pasar di Kabupaten Bogor. Masyarakat juga makin pintar dalam mengelola informasi yang mereka dapatkan sehingga public relations mengalami perluasan dalam peran eksternalnya. Perluasan fungsi eksternal public relations salah satunya adalah Marketing Public Relations (MPR). MPR meliputi proses merencanakan, melaksanakan dan mengevaluasi program yang mendorong pembelian dan kepuasan pengunjung melalui komunikasi informasi dan impresi kredibel. Seperti halnya iklan, hubungan masyarakat (public relations) juga menjadi kiat pemasaran penting. Fungsi public relations memiliki peran awal yang memberikan 
keuntungan kompetitif terhadap kinerja hotel yaitu meningkatkan kepuasan konsumen dan mencapai tujuan (Amaireh, 2014).

Perusahaan tidak hanya harus berhubungan secara konstruktif dengan pengunjung, pemasok dan penyalur, namun juga harus berhubungan dengan kumpulan kepentingan masyarakat besar. Banyak perusahaan kini membentuk Divisi MPR untuk mempromosikan dan menjaga citra perusahaan atau produknya. Hal tersebut disebabkan oleh kontribusi MPR pada konteks pemasaran yang telah dikenal secara luas, tidak hanya sebagai strategi pendukung, tapi juga memiliki peran strategis dalam publikasi pemasaran (Kitchen, 1996). MPR memberikan nilai tambah terhadap program komunikasi pemasaran terpadu dalam beberapa cara, yaitu membangun daya tarik pasar sebelum munculnya periklanan di media, contohnya pemberitaan mengenai produk baru yang merupakan suatu peluang bagi para pemasar untuk mendapatkan publisitas dan mendramatisasikan produk tersebut sehingga akan meningkatkan keefektifan dari iklan tersebut.

Menyadari akan pentingnya peranan MPR dalam rangka menciptakan citra yang positif bagi perusahaan, maka MPR harus dapat menjadi informan yang baik bagi perusahaan. Proses MPR terdiri dari langkah-langkah yaitu penelitian, membentuk tujuan pemasaran, menetapkan audiens sasaran, memilih pesan dan alat public relations, mengimplementasikan rencana public relations serta mengevaluasi hasil (Kotler, 2003). MPR akan memahami kondisi perusahaan bila perusahaan memberikan kesempatan pada MPR untuk menerima masukan, mengolahnya dan kemudian mengintegrasikannya dengan program perusahaan. Hal ini bertujuan agar MPR dapat memberikan informasi berimbang, komunikatif dan mendidik bagi publik.

Citra positif dapat terbentuk apabila publik mempunyai persepsi yang positif terhadap perusahaan. Agar hal tersebut tercapai, maka publik harus dalam keadaan informasi yang cukup (well informed) tentang perusahaan (Gultom, 2013). Citra merupakan hal penting bagi perusahaan di industi hotel, sehingga perusahaan perlu melakukan berbagai cara dengan membentuk pelayanan prima oleh pekerja hotel sebagai representatif hotel, sehingga konsumen akan betah dan bertahan dalam menggunakan jasa hotel di masa depan (Nurrahman, 2015). Bila tanggapan konsumen kurang baik, maka citra hotel akan menurun (Lianty \& Widayatmoko, 2011).

Berdasarkan pertimbangan tersebut, penelitian ini dilaksanakan guna menganalisis pengaruh peran MPR yang dilaksanakan oleh LLRC sehingga dapat meningkatkan citra positif, goodwill, kepercayaan, serta penghargaan dari publik. Dengan hal itu, LLRC dapat menghadapi persaingan bisnis saat ini dan implikasinya dapat memenangkan persaingan dalam industri perhotelan. Secara lebih rinci, tujuan dari penelitian ini adalah: (1) Menganalisis karakteristik konsumen hotel LLRC Sukabumi dan (2) Menganalisis pengaruh variabel Marketing Public Relations (MPR) terhadap peningkatan citra yang positif bagi LLRC.

\section{METODE PENELITIAN}

Tingkat persaingan dan semakin kompleksnya industri perhotelan membuat LLRC harus meningkatkan citra perusahaan agar mampu bersaing diindustri perhotelan. Perusahaan perlu memperhatikan peranan dari MPR untuk mengetahui pengaruh MPR terhadap peningkatan citra perusahaan. Komponen MPR meliputi publikasi, events, berita, kegiatan sosial, dan media identitas (Kotler,2002).

Publikasi merupakan materi komunikasi agar dapat meraih dan mempengaruhi pasar sasaran. Hal yang termasuk dalam publikasi adalah laporan tahunan, brosur, kartu, artikel, materi audio visual, newsletter dan majalah perusahaan. Acara khusus yang diadakan perusahaan dapat menarik perhatian pasar. Berita adalah salah satu usaha public relations untuk membuat atau mencari acara/kegiatan yang sesuai dengan perusahaan, produk, orang dan karyawannya, serta membuat media tertarik untuk membuat press release dan datang pada acara press conference yang diadakan perusahaan (Kotler \& Keller, 2007). Sedangkan pengertian dari kegiatan sosial dalam perspektif PR adalah perusahaan ikut serta dalam aktivitas kegiatan sosial masyarakat untuk membangun citra positif. Perusahaan besar akan mendukung kegiatan sosial 
dalam lingkungan perusahaannya atau akan mendonasikan uangnya untuk tujuan tertentu (Wijaya \& Kismiyati, 2013). Media identitas adalah kebutuhan perusahaan untuk menciptakan identitas yang mudah dikenal masyarakat. Perusahaan harus menciptakan identitas visual di mana publik mengenalinya. Identitas visual suatu perusahaan dapat berupa logo, alat tulis, brosur, tanda, kartu nama, bangunan, seragam, atau kode etik berpakaian (Gaffar, 2007).

Penelitian ini menggunakan analisis Structural Equation Model (SEM) menggunakan alat bantu Software Smart PLS untuk menganalisis pengaruh MPR meliputi lima indikator tersebut terhadap peningkatan citra perusahaan. Penelitian ini diharapkan dapat dijadikan rekomendasi bagi LLRC untuk meningkatkan citra perusahaannya. Berdasarkan uraian tersebut, maka dapat dibuat bagan alir kerangka pemikiran penelitian yang disajikan dalam Gambar 1.

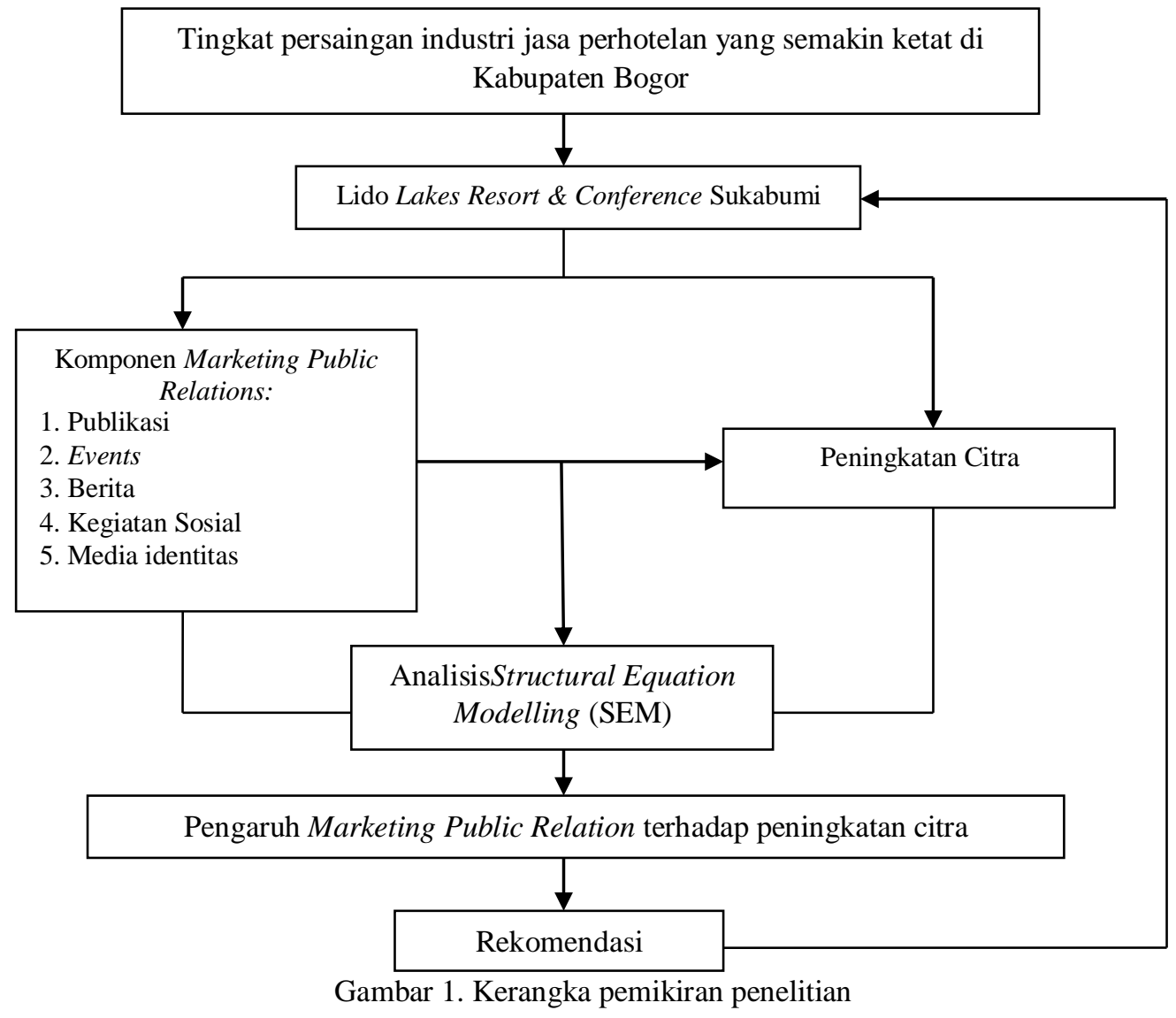

Penelitian ini dilaksanakan di Lido Lakes Resort \& Conference (LLRC) Sukabumi yang beralamat di Jl. Raya Bogor-Sukabumi KM. 21, Kabupaten Bogor-Jawa Barat. Jenis data yang digunakan adalah data primer dan sekunder. Data primer didapat dari narasumber atau responden melalui studi lapangan atau observasi langsung ke lapangan, dan wawancara. Data sekunder yang digunakan adalah literatur, buku, dan buku pustaka lainnya yang mendukung penelitian. Populasi penelitian adalah pengunjung di hotel LLRC dengan membagikan kuesioner kepada konsumen yang sedang pernah dan mengunjungi hotel LLRC.

Metode pengambilan sampel pada penetilian ini adalah menggunakan teknik non probability sampling yaitu convenience sampling. Jumlah sampel ditentukan dengan menggunakan rumus Slovin dengan tingkat kepercayaan 95 persen sehingga nilai error (e) adalah sebesar 0,05 . Jumlah populasi adalah sebanyak 1.600 orang, sehingga hasil perhitungan rumus Slovin menyatakan bahwa sampel penelitian ini adalah 95 orang sampel.

Metode pengolahan dan analisis data pada penelitian dimulai dari analisis deskriptif. Menurut Sugiyono (2014), analisis deskriptif adalah analisis statistik yang berfungsi untuk mendeskripsikan atau memberi gambaran terhadap obyek yang diteliti melalui data sampel atau populasi sebagaimana adanya, tanpa melakukan analisis dan membuat kesimpulan yang berlaku 
untuk umum. Structural Equation Modelling (SEM) dengan pendekatan Partial Least Square (PLS) digunakan dalam penelitian ini untuk menganalisis pengaruh peran MPR terhadap peningkatan citra hotel LLRC.

\section{HASIL DAN PEMBAHASAN}

\section{Gambaran Umum Hotel Lido Lakes Resort \& Conference (LLRC) Sukabumi}

Lido Resort dibangun pada tahun 1935 oleh Warga Negara Belanda bernama Antonius Ludoficus Maria Zwijsen yang digunakan sebagai tempat peristirahatan dan rekreasi dengan gaya arsitektur Belanda. Tahun 1940, Lido Resort diresmikan sebagai penghormatan terhadap Ratu Wilhelmina. Selama Perang Dunia II, Hotel Lido dan Hotel Royal dihancurkan oleh Jepang dan daerah Lido dikuasai Jepang tahun 1942-1944. Namun kemudian diambil alih oleh KNI, BKR, TKR, TRI, dan pejuang kelaskaran antara tahun 1945-1946. Setelah proklamasi kemerdekaan Indonesia, nama Lido Resort berubah menjadi Lido Megawati dan menjadi tempat peristirahatan Presiden RI pertama yaitu Soekarno.

Di bawah PT. PAP, Lido diproyeksikan menjadi kawasan resort dengan konsep agrowisata. PT. PAP melakukan langkah-langkah pengembangan Lido, salah satunya dengan membangun hotel berbintang empat bertaraf internasional beserta fasilitas-fasilitas pendukung seperti lapangan golf dan berbagai kegiatan luar rungan lainnya (outdoor activities).

LLRC dibangun di atas tanah seluas 2,2 hektar, dengan luas bangunan $20.000 \mathrm{~m}^{2}$. Hotel yang dibangun dengan konsep resort dan conference ini secara resmi mulai beroperasi tanggal 1 Juni 1995. Berdasarkan survei yang telah dilakukan, hotel ini dapat dikategorikan sebagai hotel semi internasioanal karena hotel LLRC hotel bintang empat, jika dilihat dari jumlah kamar LLRC tergolong dalam large hotel yaitu hotel dengan jumlah kamar diatas 100 kamar ke atas, dan dilihat dari jenis tamu untuk menginap hotel LLRC ini sebagai tourism and business hotel.

\section{Bauran Pemasaran Lido Lakes Resort \& Conference Sukabumi}

\section{Product (Produk)}

Hotel LLRC memiliki 104 kamar dengan lima tipe kamar yaitu: Superior, Deluxe, HalimunSuite dan Lido Suite. Pada meeting room hotel LLRC memiliki enam ruangan yang terdiri dari Mahoni Ballroom, Damar, Ebony, Cendana, Meranti dan Board Room. Selain itu, produk yang ditawarkan hotel LLRC adalah restoran, business center, drug store, karaoke, lounge \& bar, golf \& driving range, outbond dan mini golf.

2. Place (Tempat)

Hotel LLRC yang bertempat di Jl. Raya Bogor-Sukabumi Km 21, Kabupaten Bogor ini sebagai tempat yang terkenal dengan keindahannya. Hotel ini adalah satu-satunya di Kabupaten Bogor dan sekitarnya di pinggir danau dan tempat wisata.

3. Promotion (Promosi)

LLRC memberikan promo harga yang berbeda untuk waktu tertentu, seperti liburan sekolah, liburan tahun baru, liburan hari lebaran dan kerjasama dengan beberapa mass media (koran, radio, majalah, televisi, dan internet).

4. Price (Harga)

Harga jasa penginapan yang ditetapkan oleh LLRC berkisar antara Rp767.800 untuk kamar superior hingga yang paling mahal yaitu Rp3.052.500 untuk lido suite. Terdapat tambahan harga untuk extra bed sebesar Rp150.000 dan harga sudah termasuk pajak dan akomodasi dasar.

5. Process (Proses)

Perusahaan menggunakan format ISO 9001: 2000 yang digabungkan dengan format SKKNI sehingga menghasilkan suatu Standard Operation Procedure (SOP). SOP kemudian dikembangkan menjadi beberapa standar kerja yang dibukukan sebagai pedoman dalam pelaksanaan operasional perusahaan. 
6. Productivity and Quality (Produktivitas dan Kualitas)

Tingkat produktivitas penjualan jasa kamar dalam industry perhotelan diukur berdasarkan tingkat hunian kamar hotel. Produktivitas hotel LLRC dalam penjualan jasa kamar dan ruang meeting memiliki rata-rata 60 persen occupancy.

7. People (Orang)

Setiap pegawai hotel LLRC terutama pegawai front liner seperti receptionist, bellboy atau roomboy, house keeping diwajibkan memperlihatkan citra yang baik, sopan dan rapi sebagai bentuk representatif perusahaan dimata pelanggan.

8. Physical Evidence (Bukti Fisik)

LLRC merupakan hotel berbintang empat dengan konsep resort. Dengan bangunan fisik luar bangunan zaman Belanda, semua kamar di hotel dikelilingi oleh Danau Lido, Gunung Salak, gunung Gede dan Gunung Pangrango ini memiliki sentuhan desain tradisional dengan jendela lebar ditambah balkon untuk menikmati keindahan alam yang menakjubkan.

\section{Analisis Karakteristik Responden}

Berdasarkan hasil analisis menunjukkan bahwa responden hotel LLRC didominasi oleh remaja laki-laki dengan rentan usia 20-25 tahun, dikarenakan kaum muda tertarik dengan suasana alam yang ditawarkan oleh pihak hotel LLRC, sedangkan domisili luar bogor karena ingin mencoba suasana baru dan mencari lingkungan lebih hijau dengan tarif harga menginap dihotel LLRC sebesar Rp700.000-Rp3.000.000. Wajar bila pekerjaan PNS lebih dominan dikarenakan adanya sponsor yang menunjang para PNS untuk mengunjungi hotel LLRC.

\section{Analisis Perilaku Pembelian}

Perilaku pembelian pengunjung hotel LLRCdibagi berdasarkan bagaimana responden memperoleh informasi, ketertarikan responden mengunjungi hotel saat pertama kali, klasifikasi kegiatan responden mengunjungi hotel, fasilitas lain yang digunakan responden, lama waktu responden mengunjungi hotel dan pilihan mengunjungi hotel lain.

Hasil analisis menunjukkan bahwa mayoritas konsumen mendapat informasi mengenai hotel LLRC dari teman atau kerabat (54,73 persen). Mayoritas konsumen tertarik mengunjungi hotel LLRC saat pertama kali karena diajak atau direkomendasikan teman (42,10 persen) dengan tujuan kunjungan ke hotel LLRC adalah menginap dan meeting (33,68 persen). Fasilitas lain yang dicoba mayoritas konsumen hotel LLRC adalah restaurant $(42,10$ persen) dengan lama menginap selama dua hari $(57,89$ persen). Pilihan hotel selain LLRC yang dipilih mayoritas konsumen adalah hotel Jayakarta (34,73 persen).

\section{Analisis Deskriptif Persepsi Responden terhadap MPR dan Citra Hotel Lido Lakes Resort \& Conference (LRLC)}

Persepsi responden mengenai variabel MPR dan citra hotel mendapatkan beberapa penilaian dari responden. Penilaian persepsi terhadap marketing public relations dan citra hotel dapat dilihat pada Tabel 5.

Tabel 5. Penilaian persepsi terhadap MPR dan citra hotel

\begin{tabular}{|c|c|c|c|c|c|}
\hline Variabel & Indikator & $\begin{array}{c}\text { Rataan } \\
\text { Skor } \\
\text { Indikator }\end{array}$ & Keterangan & $\begin{array}{c}\text { Rataan } \\
\text { Skor } \\
\text { Variabel }\end{array}$ & Keterangan \\
\hline \multirow{3}{*}{ Publikasi } & Tertarik untuk membaca & 3,26 & Kurang setuju & \multirow{3}{*}{3,61} & \multirow{3}{*}{ Setuju } \\
\hline & Mampu memahami isi & 3,76 & Setuju & & \\
\hline & Media informasi & 3,8 & Setuju & & \\
\hline \multirow{3}{*}{ Events } & Representatif setiap events & 3,82 & Setuju & \multirow{3}{*}{3,60} & \multirow{3}{*}{ Setuju } \\
\hline & Acara tahunan menarik & 3,8 & Setuju & & \\
\hline & Frekuensi events & 3,18 & Kurang setuju & & \\
\hline \multirow{3}{*}{ Berita } & $\begin{array}{l}\text { Mengetahui informasi } \\
\text { hotel }\end{array}$ & 3,6 & Kurang setuju & \multirow{3}{*}{3,80} & \multirow{3}{*}{ Setuju } \\
\hline & Press release & 3,57 & Kurang setuju & & \\
\hline & $\begin{array}{l}\text { Mencari informasi dengan } \\
\text { mudah }\end{array}$ & 4,22 & Sangat setuju & & \\
\hline
\end{tabular}




\begin{tabular}{|c|c|c|c|c|c|}
\hline Variabel & Indikator & $\begin{array}{l}\text { Rataan } \\
\text { Skor } \\
\text { Indikator }\end{array}$ & Keterangan & $\begin{array}{l}\text { Rataan } \\
\text { Skor } \\
\text { Variabel }\end{array}$ & Keterangan \\
\hline \multirow{3}{*}{$\begin{array}{l}\text { Kegiatan } \\
\text { Sosial }\end{array}$} & $\begin{array}{l}\text { Merupakan tempat untuk } \\
\text { kegiatan social }\end{array}$ & 2,86 & Kurang setuju & \multirow{3}{*}{2,85} & \multirow{3}{*}{ Kurang setuju } \\
\hline & Mengenal sebagai donator & 2,75 & Kurang setuju & & \\
\hline & $\begin{array}{l}\text { Mengetahui membantu } \\
\text { korban bencana }\end{array}$ & 2,95 & Kurang setuju & & \\
\hline \multirow{2}{*}{$\begin{array}{l}\text { Media } \\
\text { Identitas }\end{array}$} & $\begin{array}{l}\text { Merupakan nama yang } \\
\text { tepat }\end{array}$ & 4,38 & Sangat setuju & \multirow{2}{*}{4,08} & \multirow{2}{*}{ Setuju } \\
\hline & $\begin{array}{l}\text { Mengagumi bangunan } \\
\text { fisik }\end{array}$ & 3,78 & Setuju & & \\
\hline \multirow{4}{*}{$\begin{array}{l}\text { Citra } \\
\text { Hotel }\end{array}$} & $\begin{array}{l}\text { Tertarik menggunakan } \\
\text { produk }\end{array}$ & 3,77 & Setuju & \multirow{4}{*}{3,65} & \multirow{4}{*}{ Setuju } \\
\hline & Nyaman terhadap layanan & 3,74 & Setuju & & \\
\hline & $\begin{array}{l}\text { Mengatakan hal positif } \\
\text { Merupakan pilihan }\end{array}$ & 3,82 & & & \\
\hline & pertama & 3,27 & Kurang setuju & & \\
\hline
\end{tabular}

Sumber: Data diolah (2016)

Berdasarkan Tabel 5, persepsi responden terhadap variabel publikasi memperoleh ratarata penilaian sebesar 3,61 yang berarti secara keseluruhan penilaian responden terhadap publikasi berada pada kategori setuju $(3,40-4,20)$. Persepsi responden terhadap events memperoleh rata-rata penilaian sebesar 3,60 yang berarti secara keseluruhan penilaian responden terhadap events berada pada kategori setuju $(3,40-4,20)$. Berita memperoleh rata-rata penilaian sebesar 3,80 yang berarti secara keseluruhan penilaian responden terhadap berita berada pada kategori setuju $(3,40-4,20)$. Kegiatan sosial memperoleh rata-rata penilaian sebesar 2,85 yang berarti secara keseluruhan penilaian responden terhadap kegiatan sosial pada kategori kurang setuju $(2,60-3,40)$. Persepsi responden terhadap media identitas memperoleh rata-rata penilaian sebesar 4,08 yang berarti secara keseluruhan penilaian responden terhadap media identitas berada pada kategori setuju $(3,40-4,20)$. Sedangkan untuk citra hotel memperoleh ratarata penilaian sebesar 3,65 yang berarti secara keseluruhan penilaian terhadap citra hotel pada kategori setuju $(3,40-4,20)$.

\section{Analisis Pengaruh Peran MPR tehadap Citra Hotel Lido Lakes Resort \& Conference (LLRC)}

Analisis SEM dalam penelitian ini menggunakan metode Partial Least Square dengan bantuan software SmartPLS 3.0. Terdapat dua langkah evaluasi dalam melakukan analisis menggunakan SEM-PLS yaitu evaluasi model pengukuran atau outer model dimana dilakukan untuk mengetahui hubungan antara variabel laten dengan indikatornya serta untuk menilai validitas dan reliabilitas model. Evaluasi selanjutnya yaitu evaluasi model struktural atau inner model yang bertujuan untuk menganalisis hubungan antar variabel laten.

Analisis Evaluasi Model Pengukuran (Outer Model)

Analisis outer model dilakukan dengan menganalisis nilai validitas dan composite reliability. Untuk melihat model akhir SEM setelah melakukan proses dropping dapat dilihat pada Gambar 3. 


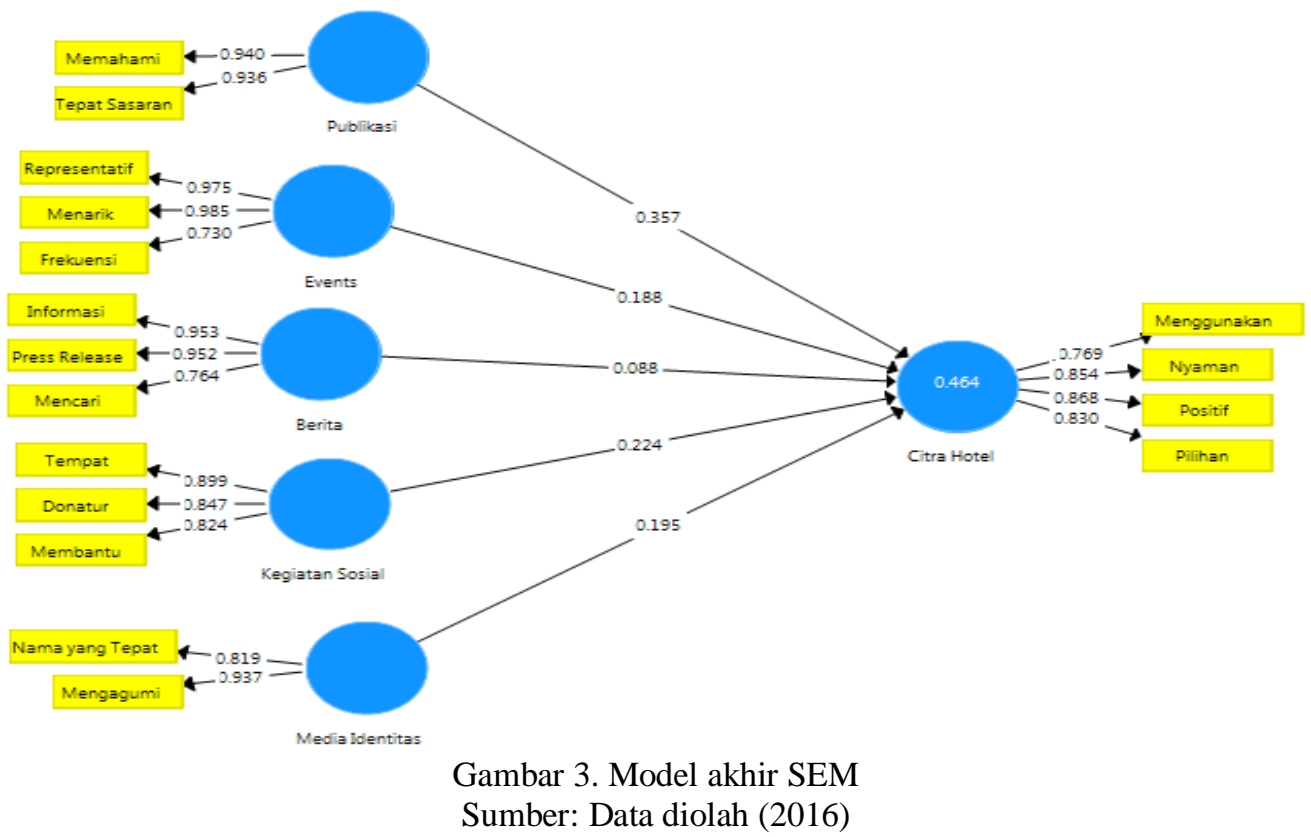

Berdasarkan Gambar 3 diketahui bahwa dropping dilakukan terhadap indikator yang memiliki nilai loading factor kurang dari 0,70. Terdapat satu indikator yang nilai loading factornyakurang dari 0,70, yaitu indikator tertarik pada variabel publikasi. Sedangkan terdapat 17 indikator yang memiliki nilai loading factor lebih dari 0,70 yang hasilnya disajikan pada Tabel 6.

Tabel 6. Indikator yang memiliki nilai loading factor lebih dari 0.70

\begin{tabular}{cccc}
\hline Variabel & Indikator & Nilai Loading Factor & Keterangan \\
\hline \multirow{2}{*}{ Publikasi } & Memahami & 0,940 & Memenuhi Syarat \\
& Tepat Sasaran & 0,936 & Memenuhi Syarat \\
\hline \multirow{3}{*}{ Events } & Representatif & 0,975 & Memenuhi Syarat \\
& Menarik & 0,985 & Memenuhi Syarat \\
& Frekuensi & 0,730 & Memenuhi Syarat \\
\hline \multirow{2}{*}{ Berita } & Informasi & 0,953 & Memenuhi Syarat \\
& Press Release & 0,952 & Memenuhi Syarat \\
& Mencari & 0,764 & Memenuhi Syarat \\
\hline \multirow{3}{*}{ Kegiatan Sosial } & Tempat & 0,899 & Memenuhi Syarat \\
& Donatur & 0,847 & Memenuhi Syarat \\
& Membantu & 0,824 & Memenuhi Syarat \\
\hline \multirow{2}{*}{ Media Identitas } & Nama yang Tepat & 0,819 & Memenuhi Syarat \\
& Mengagumi & 0,937 & Memenuhi Syarat \\
\hline \multirow{3}{*}{ Citra Hotel } & Menggunakan & 0,769 & Memenuhi Syarat \\
& Nyaman & 0,854 & Memenuhi Syarat \\
& Positif & 0,868 & Memenuhi Syarat \\
& Pilihan & 0,830 & Memenuhi Syarat \\
\hline
\end{tabular}

Sumber: Data diolah (2016)

Berdasarkan Tabel 6, publikasi dan media identitas memiliki dua indikator yang memiliki nilai loading factor lebih dari 0,70 , sedangkan vents, berita dan kegiatan sosial memiliki tiga indikator dan citra hotel memiliki empat indikator. Setelah melakukan proses dropping terhadap indikator yang memiliki nilai kurang dari 0,70 maka evaluasi outer model dapat dilanjutkan ke 
Tabel 7. Hasil analisis outer model

\begin{tabular}{|c|c|c|c|c|}
\hline $\begin{array}{l}\text { Validitas dan } \\
\text { Reliabilitas }\end{array}$ & Parameter & Syarat & Hasil Penilaian & Keterangan \\
\hline \multirow{7}{*}{ Validitas } & Loading factor & $>0,7$ & $\begin{array}{l}\text { Pada Gambar } 4, \text { semua } \\
\text { loading factor telah lebih dari } \\
0,70\end{array}$ & Memenuhi Syarat \\
\hline & \multirow{6}{*}{$\begin{array}{c}\text { Average Variance } \\
\text { Extracted }\end{array}$} & \multirow{6}{*}{$>0,5$} & Publikasi $=0,879$ & \multirow{6}{*}{ Memenuhi Syarat } \\
\hline & & & Events $=0,817$ & \\
\hline & & & Berita $=0,800$ & \\
\hline & & & Kegiatan Sosial $=0,735$ & \\
\hline & & & Media Identitas $=0,775$ & \\
\hline & & & Citra Hotel $=0,691$ & \\
\hline \multirow{6}{*}{ Reliabilitas } & \multirow{6}{*}{$\begin{array}{l}\text { Composite } \\
\text { Realibility }\end{array}$} & \multirow{6}{*}{$>0,7$} & Publikasi $=0,936$ & \multirow{6}{*}{ Memenuhi Syarat } \\
\hline & & & Events $=0,930$ & \\
\hline & & & Berita $=0,922$ & \\
\hline & & & Kegiatan Sosial $=0,892$ & \\
\hline & & & Media Identitas $=0,873$ & \\
\hline & & & Citra Hotel $=0,899$ & \\
\hline
\end{tabular}

Sumber: Data diolah (2016)

Berdasarkan Tabel 7 diketahui bahwa hasil dari evaluasi outer model dalam penelitian ini telah valid dan reliabel.

Analisis Evaluasi Model Struktural (Inner Model)

Evaluasi model struktural (inner model) pada prinsipnya bertujuan untuk menguji adanya pengaruh positif atau negatif antara satu variabel independen dengan variabel dependen. Pengujian dilakukan dengan melihat output SmartPLS dari nilai bootstrapping antar-konstruk. Pengaruh variabel independen secara keseluruhan terhadap variabel dependen dapat dilihat dari nilai $R$-Square $\left(\mathrm{R}^{2}\right)$.

Hasil analisis menunjukkan bahwa nilai $R$-square sebesar 0,464 yang berarti bahwa semua variabel independen (publikasi, event, berita, kegiatan sosial, dan media identitas) secara simultan mampu menjelaskan variablel dependen (citra hotel) sebesar 46,4 persen, sedangkan sisanya sebesar 53,6 persen dijelaskan oleh variabel lain yang tidak dirumuskan dalam model ini.

Uji selanjutnya pada evaluasi model struktural adalah melihat nilai estimasi koefisien jalur meliputi pengaruh positif langsung masing-masing variabel independen dengan variabel dependen. Evaluasi ini melihat hasil output SmartPLS pada path coeficients. Pengujian hipotesis yang dilakukan dilihat dari nilai t-Statistik. Batas untuk menolak atau menerima hipotesis yang diajukan adalah t-statistik 1,96 untuk two-taiedt-test dan tingkat signifikansi 5 persen. Hasil path coefficients disajikan pada Tabel 8.

Tabel 8.Hasil path coefficients

\begin{tabular}{ccccc}
\hline Keterangan & $\begin{array}{c}\text { Original } \\
\text { Sample }\end{array}$ & t-statistik & Hipotesis & Keterangan \\
\hline Publikasi -> Citra Hotel & 0,357 & 3,491 & Tolak $\mathrm{H}_{0} 1$ & Positif Signifikan \\
Events $->$ Citra Hotel & 0,188 & 1,830 & Terima $\mathrm{H}_{0} 2$ & Tidak Signifikan \\
Berita -> Citra Hotel & 0,088 & 0,944 & Terima $\mathrm{H}_{0} 3$ & Tidak Signifikan \\
Kegiatan Sosial -> Citra Hotel & 0,224 & 2,547 & Tolak $\mathrm{H}_{0} 4$ & Positif Signifikan \\
Media Identitas -> Citra Hotel & 0,195 & 2,107 & Tolak $\mathrm{H}_{0} 5$ & Positif Signifikan \\
\hline
\end{tabular}

Sumber: Data diolah (2016)

Berdasarkan Tabel 8, publikasi, kegiatan sosial, dan media identitas berpengaruh positif secara signifikan terhadap peningkatan citra hotel. Sedangkan variabel events, dan berita, tidak berpengaruh secara signifikan terhadap peningkatan citra hotel. 


\section{Implikasi Manajerial}

Berdasarkan analisis deskriptif persepsi responden terhadap MPR dan citra hotel, diketahui bahwa terdapat tiga variabel dengan indikator berbeda yang harus ditingkatkan oleh LLRC. Untuk mencapai kualitas yang lebih baik, MPR disarankan untuk:

1. Meningkatkan publikasi yang menarik agar mengundang konsumen selalu tertarik untuk untuk membaca artikel, brosur, dan newsletter mengenai hotel. Selain itu, pakar PR mulai menambah saluran blog untuk memperlihatkan produk dan publikasinya kepada konsumen agar meningkatkan citra organisasi (Alhadid \& Qaddomi, 2016).

2. LLRC harus bisa menjadi tempat yang pertama dalam melakukan kegiatan sosial yang mencakup daerah sekitar Kabupaten Bogor. Kemudian dari kegiatan ini dibuat press release yang dapat dipublikasikan kepada masyarakat sebagai informasi penting yang dapat disampaikan melalui media. Hal ini dilakukan untuk membangun brand awareness kepada publik tentang hotel ini (Puspokusumo, 2011).

3. LLRC harus menyanggupi sebagai donatur pada suatu kegiatan terutama untuk daerah Kabupaten Bogor (sponsorship). Paket sponsorship yang dikemas secara tepat dapat menciptakan dan memperkuat kesadaran konsumen tentang image perusahaan yang tinggi. Sebagai sebuah taktik, sponsorship memiliki kelebihan yaitu mampu menempatkan produk pada lingkungan yang tidak terlalu banyak persaingan, sedangkan kelemahannya yaitu kurang menarik khalayak (Rifon et al., 2004). Oleh karena itu penting bagi pihak LLRC untuk fokus memberikan sponsorship pada event dan kemampuan dalam meyakinkan pasar sasaran.

4. Membawakan media identitas LLRC untuk terus dipromosikan kepada masyarakat. Media identitas yang melekat pada LLRC adalah kata Lido pada hotel ini, dimana hal tesebut berhubungan dengan nama danau di Sukabumi yaitu Danau Lido. Lokasinya yang dekat dengan Danau Lido dan Jalan Raya Bogor-Sukabumi membuat lokasi hotel terbukti strategis dan mampu memberikan suasana pedesaan yang sejuk dan nyaman kepada konsumen untuk menginap. Sehingga diharapkan dapat meningkatkan dan menjaga loyalitas pelanggan melalui citra perusahaan yang sudah terbentuk sangat baik saat ini (Veliyanti et al., 2014)

Berdasarkan hasil pembahasan dan analisis data, diketahui bahwa variabel publikasi, kegiatan sosial dan media identitas memiliki pengaruh signifikan terhadap peningkatan citra hotel. Kondisi ini harus dipertahankan dan terus ditingkatkan oleh perusahaan mengingat dampak dari kegiatan-kegiatan yang menghasilkan efek positif terhadap peningkatan citra hotel. Sedangkan variabel events dan berita memiliki pengaruh tidak signifikan terhadap peningkatan citra hotel. Kondisi ini mungkin disebabkan pihak hotel Lido Lakes Resort \& Conference kurang menarik dalam menyelenggarakan events dan perusahaan kurang memahami kebutuhan pengunjung akan berita yang menarik. Berdasarkan hasil tersebut dapat disimpulkan bahwa variabel events dan berita tidak memengaruhi peningkatan citra hotel. Pembeli dalam pasar industri harus lebih kritis dalam menanggapi penawaran produk yang dilakukan pemasar.

\section{KESIMPULAN}

Berdasarkan hasil penelitian maka dapat disimpulkan bahwa karakteristik responden hotel LLRC didominasi oleh remaja laki-laki dengan rentan usia 20-25 tahun dikarenakan kaum muda tertarik dengan suasana alam yang ditawarkan oleh pihak hotel LLRC, sedangkan responden yang berdomisili luar bogor memiliki motivasi untuk berkunjung karena ingin mencoba suasana baru dan mencari lingkungan yang lebih hijau.Tarif harga menginap dihotel LLRC yang dipilih mayoritas adalah sebesar Rp700.000,00-Rp3.000.000,00. Dominasi responden adalah memiliki pekerjaan PNS, dikarenakan adanya sponsor yang menunjang para PNS untuk mengunjungi hotel LLRC. Berdasarkan hasil analisis yang dilakukan pada penelitian ini, komponen MPR publikasi, kegiatan sosial, dan media identitas memiliki pengaruh positif dan signifikan terhadap peningkatan citra hotel LLRC, sehingga pengaruh yang ada dapat

digeneralisasi. Pada hasil $\mathrm{R}^{2}$ sejumlah 46,4 persen, variabel publikasi, event, berita, kegiatan sosial, dan media identitas dapat menjelaskan variabel citra hotel LLRC. 


\section{DAFTARPUSTAKA}

Agusnawar, A. (2004). Resepsionis Hotel. Jakarta: PT Gramedia Pustaka Utama.

Alhadid, A. Y, \& Qaddomi, B. A. (2016). The role of public relations on company image: Social media as a moderating variable: A case study at the applied science Private University at Jordan. International Journal of Academic Research in Progressive Education and Development, 6(4), 1-8.

Alhroot, A. H. H., \& Alhroot, H.A. (2013). The impact of entrepreneurship over tourism for the destination marketing of Jordan. International Journal of Academic Research in Progressive Education and Development, 2(1), 1-17.

Amaireh, A. F. A. L. (2014). Measuring the impact of public relations function on the performance of the Jordanian Hotels. International Journal of Innovative Research in Science, Engineering and Technology, 3(9), 1-9.

[BPS] Badan Pusat Statistik. Statistik Hotel dan Akomodasi Lainnya di Indonesia Tahun 20092013. (2014). Jakarta: Badan Pusat Statistik.

[BPS KAB BOGOR] Badan Pusat Statistik Kabupaten Bogor. (2014). Kabupaten Bogor dalam Angka 2014. Bogor: Badan Pusat Statistik Kabupaten Bogor.

[BPS KAB BOGOR] Badan Pusat Statistik Kabupaten Bogor. (2015). Statistik Daerah Kabupaten Bogor Tahun 2015. Bogor: Badan Pusat Statistik Kabupaten Bogor.

Gaffar, V. (2007). CRM dan MPR Hotel. Bandung: Alfabeta.

Gultom, S. R. A. (2013). Citra yang ditampilkan perusahaan dalam press release (Studi analisis isi mengenai jenis release dan jenis citra yang ditampilkan public relations officerSantika Premiere Dyandra Hotel \& Convention Medan dalam press release. E-Journal Universitas Sumatera Utara, 1(2), 1-10.

Kitchen, P. (1996). Public relations in the promotional mix: a three-phase analysis", Marketing Intelligence \& Planning Journal, 14(2), 5-12.

Kotler, P. (2002). Manajemen Pemasaran Edisi Millenium. Jakarta: PT Prenhallindo. . (2003). Manajemen Pemasaran: Analisis, Perencanaan, Implementasi dan Kontrol. Edisi ke Sembilan Jilid satu. Jakarta: PT Prenhallindo.

Kotler, P., \& Keller, K. L. (2007). Manajemen Pemasaran Edisi 12. Jakarta: Indeks.

Lianty, Y., \& Widayatmoko. (2011). Analisis empiris pengaruh public relations terhadap citra Hero Supermarket. Jurnal Komunikasi Universitas Tarumanegara. 3(1), 1-12.

Nurrahman, M. A. (2015). Strategi marketing public relations The Sun Hotel Sidoarjo pada publik konsumen. E-Journal UNAIR, 4(2), 287-302.

[Pusdatin Kemenparekraf] Pusat Data dan Informasi Kementrian Pariwisata dan Ekonomi Kreaktif. (2014). Perkembangan Wisatawan Nasional Tahun 2009-2013. Jakarta: Pusat Data dan Informasi Kementrian Pariwisata dan Ekonomi Kreaktif.

Puspokusumo, A. (2011). Peranan management public relations dalam mempertahankan citra perusahaan jasa perhotelan: Studi kualitatif pada re-opening Hotel Mandarin Oriental, Jakarta. Binus Business Review, 2 (1), 1-14.

Rifon, N. J., Choi, S. M., Trimble, C. S., \& Li, H. (2004). Conqruence effect in sponsorship: The mediatting role sponsor credibility and consumer attributions of sponsor motive. Journal of Advertising, 2(1), 1-13.

Sugiyono. (2014). Metode Penelitian Manajemen. Bandung: Alfabeta.

Veliyanti, T. A., Arifin, Z., \& Yulianto, E. (2014). Pengauh marketing public relations tehadap citra perusahaan dan dampaknya terhadap loyalitas pelanggan (Survei pada pelanggan Toyota Auto 2000 Jl. Letjend Sutoyo No, 25, Malang). Jurnal Administrasi Bisnis, 11(1), $1-9$.

Wijaya, L. S., \& Kismiyati. (2013). Identifying marketing public relations strategies implemented in private universities for increasing students intake in Central JavaIndonesia. Reseachers World - Journal of Arts, Science \& Commerce, 4(2), 1-7. 